\title{
Effect of Sire Fertility and Timing of Artificial Insemination in a Presynch + Ovsynch Protocol on First-Service Pregnancy Rates
}

\author{
J. M. Cornwell, ${ }^{*}$ M. L. McGilliard, ${ }^{*}$ R. Kasimanickam, $†$ and R. L. Nebel ${ }^{\star 1,2}$ \\ *Department of Dairy Science, and \\ †Department of Large Animal Clinical Sciences, Virginia Polytechnic Institute and State University, Blacksburg 24061
}

\begin{abstract}
Sire fertility may influence pregnancy rate $(P R)$ by differences in sperm survival in the female reproductive system and time required for capacitation and transport of sperm to site of fertilization. A predicted fertility index, Estimated Relative Conception Rate, was used to select 3 high-fertility artificial insemination (AI) sires $(+3)$ and 3 average AI sires (-1). Ovulation can be predicted to occur at approximately $28 \mathrm{~h}$ following $\mathrm{GnRH}$ administration when used in an Ovsynch protocol. The objective of this study was to determine if $\mathrm{AI}$ at 2 times, 0 or $24 \mathrm{~h}$ after GnRH administration, in a Presynch + Ovsynch protocol resulted in different first-service PR when average or high-fertility sires were used. Lactating Holstein cows $(\mathrm{n}=1,457)$ from 2 dairy herds located in the Piedmont region of North Carolina were utilized for 12 mo. Timing of AI did not affect first AI PR and no interaction of sire-fertility group and timing of AI was detected. First AI PR did not differ between sirefertility groups (23.2 vs. $29.4 \%$ ) for average and highfertility groups, respectively. First-lactation cows were $53 \%$ more likely to conceive than older cows, and cows bred during April through June were 66\% less likely to become pregnant compared with cows bred from October through January. No interactions were detected among parity, season, sire-fertility group, or time of AI. Using only 3 sires per group based on Estimated Relative Conception Rate estimates resulted in large variability of sire conception within groups, although group averages differed by 6 points.
\end{abstract}

Key words: sire fertility, timing of artificial insemination, estimated relative conception rate, Presynch + Ovsynch

\section{INTRODUCTION}

Genetic selection for greater milk yield in dairy cows has compromised endocrine profiles to favor lactation

Received June 6, 2005.

Accepted February 10, 2006.

${ }^{1}$ Corresponding author: rnebel@selectsires.com

${ }^{2}$ Present address: Select Sires, Inc., 11740 U.S. 42 North, PO Box 143, Plain City, OH 43064-0143. at the expense of reproductive performance (Nebel and McGilliard, 1993; Lopez et al., 2004). An inverse relationship between milk yield and reproductive performance has been documented (Butler, 2000; Washburn et al., 2002). Increased confinement of cows and less labor devoted per cow as farms increase cow numbers has contributed to the decrease in estrus-detection rates (Britt et al., 1986; Lucy, 2001; Washburn et al., 2002). Development of timed artificial insemination (TAI) programs allow for reduced emphasis on detection of estrus because all cows are inseminated at a specific time relative to hormone injection (Pursley et al., 1995). Subsequent studies have reported various hormone injection protocols for improving pregnancy rates (PR) obtained with a single TAI (Vasconcelos et al., 1999; Portaluppi and Stevenson, 2005).

Extensive research has focused on increasing PR through cow management. Research investigating sire fertility and timing of AI interactions on conception rates $(\mathbf{C R})$ is lacking. Estimated relative conception rate (ERCR) is a measure of the fertility of an individual sire and is predictable and repeatable over the productive life of an AI sire if ample data have been collected (Clay and McDaniel, 2001). The ERCR-predicted fertility value is a 70-d nonreturn rate of an AI service sire relative to the service sires of herdmates. The nonreturn of a cow to estrus by $70 \mathrm{~d}$ assumes the cow is pregnant. A high ERCR value for a sire has economic benefit to a dairy manager because of a probable CR advantage at AI (Pecsok et al., 1994). Dairy Records Management Systems has the following recommendation for use of ERCR predicted fertility values posted on their Web site (http://www.drms.org): "The proportion of CR that can be attributed to the AI service bull is small. But, when an additional fertility advantage is needed, ERCR should identify low fertility bulls to avoid or high fertility bulls to select. In most cases, 2 bulls must be different by at least 3 ERCR points for them to be considered to have different ERCR."

High-fertility sires may provide a greater number of competent spermatozoa competing for fertilization, resulting in more accessory sperm per embryo, and increased fertilization rate. Furthermore, timing of AI, relative to onset of estrus, affects median accessory 


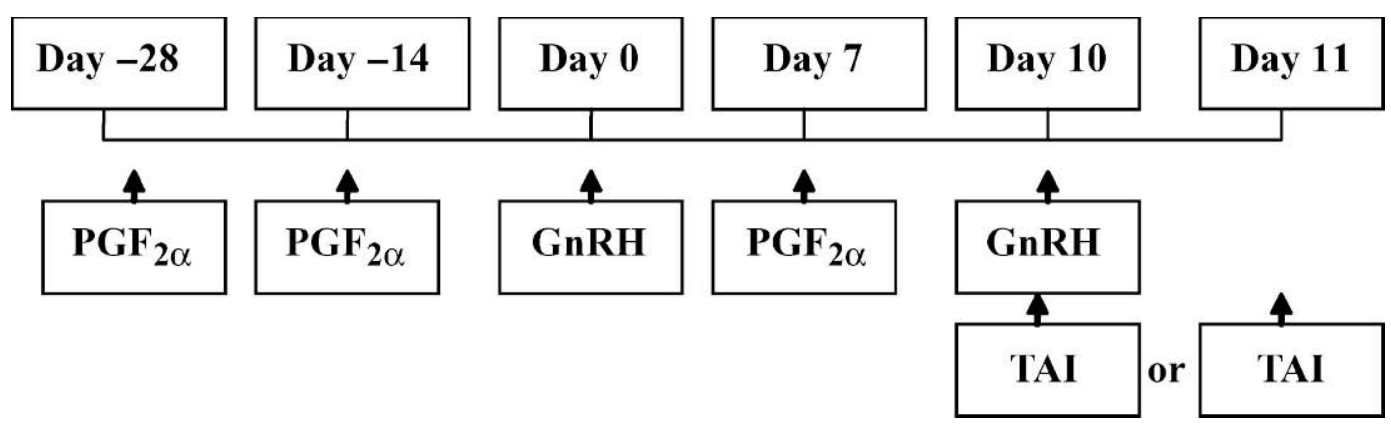

Figure 1. Diagrammatic representation of the sequence of injections administered to cows assigned to the Presynch + Ovsynch protocol. The first $\mathrm{PGF}_{2 \alpha}$ injection on d -28 was initiated between 35 and 41 DIM. All cows were administered the final GnRH on d 10, $54 \mathrm{~h}$ after $\mathrm{PGF}_{2 \alpha}$, and timed $\mathrm{AI}$ occurred at that time or $24 \mathrm{~h}$ later.

sperm per embryo or ovum (Dalton et al., 2001). Saacke et al. (1994) reported that number of accessory sperm able to reach the site of fertilization varied by individual sire. Macmillan and Watson (1975) investigated CR for sires of different fertility and reported that low-fertility sires suffered a decreased CR when AI occurred in early to midestrus, whereas no difference in CR was detected among sire-fertility groups when AI occurred in late or postestrus. Although ovulation synchronization protocols are applied to the female, ovulation synchronization should enhance accuracy and efficiency of timing of AI that are responsibilities of the male. Timing of $\mathrm{AI}$ in conjunction with very precise control of follicular development and ovulation using a protocol such as Presynch + Ovsynch, the effects of sperm longevity would tend to be minimized because even bulls with a short duration of sperm longevity might adequately cover the ovulation window to achieve acceptable conception rates.

The objective of this study was to determine if $\mathrm{AI}$ at 2 times, 0 or $24 \mathrm{~h}$ after GnRH administration, in a Presynch + Ovsynch protocol resulted in different firstservice PR when average and high-fertility sires were used.

\section{MATERIALS AND METHODS}

\section{Cows}

Lactating Holstein cows $(\mathrm{n}=1,457)$ were from 2 dairy herds located in North Carolina. Cows were housed in freestall barns and bedded on rubber mats or sand. Cows on both farms received a TMR balanced to meet or exceed the requirements for lactating dairy cows (NRC, 2001).

\section{Treatment}

Lactating dairy cows received two 25-mg injections of $\mathrm{PGF}_{2 \alpha}$, (Lutalyse, Pfizer Animal Health, New York,
NY) $14 \mathrm{~d}$ apart beginning at 35 to $41 \mathrm{DIM}$ and $100 \mu \mathrm{g}$ of GnRH (Cystorelin, Merial Ltd., Iselin, NJ) 14 d later (Figure 1). Seven days after $\mathrm{GnRH}$ administration, cows received a third 25-mg injection of $\mathrm{PGF}_{2 \alpha}$. A final injection of $100 \mu \mathrm{g}$ of $\mathrm{GnRH}$ was given $54 \mathrm{~h}$ later at 73 to 79 DIM. The time interval of $48 \mathrm{~h}$ between the final GnRH and $\mathrm{PGF}_{2 \alpha}$ injection in the standard Ovsynch protocol was increased to $54 \mathrm{~h}$ to accommodate the routine of 3 milkings per day. Cows were randomly assigned an AI time to be inseminated-at GnRH injection or $24 \mathrm{~h}$ after $\mathrm{GnRH}$ injection. Inseminations were performed by trained herd personnel and semen was thawed in a $35^{\circ} \mathrm{C}$ water bath for a minimum of $45 \mathrm{~s}$ with no more than 3 straws thawed simultaneously. Cows were restrained by headlocks or at an indexing rail to receive hormone injections and AI. Sires were selected on ERCR values (average $=-1 \mathrm{vs}$. high $=\geq+3$ ) to estimate a possible interaction of sire-fertility groups with timing of AI in a TAI protocol. Multiple ejaculates were collected in succession from each bull, evaluated singly, then pooled within bull, and processed as a single freeze code. Semen was evaluated using standard prefreeze and postthaw protocols (Genex Cooperative, Inc., Shawano, WI) and viable measurements were within normal ranges for each bull. Table 1 displays sire

Table 1. Estimated relative conception rates $(\mathrm{ERCR})^{1}$ and repeatabilities for the evaluation made immediately before the study and 6 mo later

\begin{tabular}{llllll}
\hline & \multicolumn{2}{c}{ November 2003 } & & \multicolumn{2}{c}{ May 2004 } \\
\cline { 2 - 3 } \cline { 5 - 6 } Sire & ERCR & Repeatability & & ERCR & Repeatability \\
\hline A & -1 & 99 & & -1 & 99 \\
B & -1 & 97 & & 0 & 96 \\
C & -1 & 84 & & 4 & 86 \\
D & 3 & 92 & & 2 & 86 \\
E & 3 & 92 & & 1 & 89 \\
F & 4 & 70 &
\end{tabular}

${ }^{1}$ Dairy Records Management Systems (Raleigh, NC). 
Table 2. Logistic binomial regression of pregnancy at first AI on sire-fertility group, timing of AI, parity, and season of AI, for cows mated to either sires of average- or high-fertility at either the same time or 24 $\mathrm{h}$ after the final GnRH injection

\begin{tabular}{lclllll}
\hline \multirow{2}{*}{ Source } & Category & AI (no.) & $\begin{array}{l}\text { Pregnancy } \\
\text { rate (\%) }\end{array}$ & SE (\%) & $\begin{array}{l}\text { Odds } \\
\text { ratio }^{1}\end{array}$ & $\begin{array}{l}\text { 95\% Confidence } \\
\text { interval }^{2}\end{array}$ \\
\hline Farm & 1 & 521 & 28.2 & 2.3 & 1.23 & $(0.94,1.61)$ \\
& 2 & 611 & 24.3 & 2.2 & 1.00 & \\
Fertility Group & Average & 574 & 23.2 & 2.2 & 0.73 & $(0.46,1.13)$ \\
& High & 558 & 29.4 & 2.5 & 1.00 & \\
Timing of AI after GnRH, h & 0 & 620 & 26.7 & 2.1 & 1.05 & $(0.79,1.40)$ \\
& 24 & 512 & 25.7 & 2.3 & 1.00 & \\
Lactation, no. & 1 & 469 & $31.8^{\mathrm{a}}$ & 2.5 & 1.53 & $(1.09,2.14)$ \\
& 2 & 330 & $24.0^{\mathrm{b}}$ & 2.7 & 1.04 & $(0.70,1.53)$ \\
Season $^{3}$ & $3+$ & 333 & $23.4^{\mathrm{b}}$ & 2.6 & 1.00 & \\
& 1 & 309 & $22.6^{\mathrm{a}}$ & 2.6 & 0.66 & $(0.47,0.93)$ \\
& 2 & 318 & $25.9^{\mathrm{ab}}$ & 2.8 & 0.79 & $(0.57,1.10)$ \\
\hline
\end{tabular}

\footnotetext{
${ }^{\mathrm{a}, \mathrm{b}}$ Means bearing different superscript letters within source differ $(P \leq 0.05)$.

${ }^{1}$ Odds ratio is the estimated chance of pregnancy at $\mathrm{AI}$ in a single category relative to the baseline category, considering other explanatory variables included in the model. The baseline for a particular category is represented as 1.0. Ratios exceeding 1 indicate increased probability of pregnancy, whereas ratios less than 1 indicate decreased probability of pregnancy for that category.

${ }^{2}$ Odds ratios with confidence intervals that do not include $1.00 \operatorname{differ}(P<0.05)$ from 1.00 (lower limit of interval, upper limit of interval).

${ }^{3} 1$ = April-June, 2 = July-September, and 3 = October-January.
}

fertility estimates for the 6 sires immediately before the study and 6 mo later.

Dairy Records Management Systems publishes ERCR values and repeatability in May and November of each year. Each mating was assigned to 1 of the 6 Holstein sires to minimize inbreeding and equalize sire usage. Cows without pedigree information were randomly allocated to a sire. One hundred six enrolled cows were removed by farm management before first AI or pregnancy diagnosis was performed. An additional 219 cows were not bred according to the protocol and deleted from the analysis. Cows were assumed not pregnant when reinseminated before $40 \mathrm{~d}$ after first TAI service. Pregnancy was confirmed by palpation per rectum of uterine contents approximately $40 \mathrm{~d}$ after AI by the herd veterinary practitioner.

\section{Data and Statistical Analyses}

Data were analyzed with SAS Version 9.1 for Windows (SAS Inst., Cary, NC). First AI PR was analyzed using the GLIMMIX procedure of SAS that combines logistic regression with mixed model effects. Sires were random and nested in fertility group. Interactions with farm were not significant and were deleted from the model:

$$
\begin{aligned}
& \mathrm{Y}_{\mathrm{ijk} l m n}=\mu+\mathrm{L}_{\mathrm{i}}+ \mathrm{F}_{\mathrm{j}}+\mathrm{B}_{(\mathrm{j}) \mathrm{k}}+\mathrm{T}_{1}+(\mathrm{FT})_{\mathrm{jl}}+\mathrm{P}_{\mathrm{m}}+(\mathrm{FP})_{\mathrm{jm}} \\
&+(\mathrm{TP})_{\mathrm{lm}}+(\mathrm{FTP})_{\mathrm{jlm}}+\mathrm{S}_{\mathrm{n}}+(\mathrm{FS})_{\mathrm{jn}}+(\mathrm{TS})_{\mathrm{ln}} \\
&+(\mathrm{PS})_{\mathrm{mn}}+\mathrm{E}_{\mathrm{ijklmn}}
\end{aligned}
$$

where $\mathrm{Y}=$ pregnancy outcome for a cow diagnosed approximately $40 \mathrm{~d}$ after $\mathrm{TAI}(0,1) ; \mu=$ overall mean; $\mathrm{L}_{\mathrm{i}}=$ the effect of the ith location (farm 1 or 2 ); $F_{j}=$ effect of jth sire-fertility group (high or average); $B_{(j) k}=$ random effect of bull $\mathrm{k}$ within sire-fertility group $\mathrm{j}(\mathrm{k}=1,2$, or 3 within $\mathrm{j}) ; \mathrm{T}_{1}=$ effect of the lth time of AI $(0$ or $24 \mathrm{~h})$; $\mathrm{P}_{\mathrm{m}}=$ effect of the mth parity $(1,2$, or more than 2$) ; \mathrm{S}_{\mathrm{n}}=$ the effect of the nth season of AI (April-June, JulySeptember, or October-January); $(\mathrm{FT})_{\mathrm{j} l},(\mathrm{FP})_{\mathrm{jm}},(\mathrm{TP})_{\mathrm{lm}}$, $(\mathrm{FS})_{\mathrm{jn}},(\mathrm{TS})_{\mathrm{ln}},(\mathrm{PS})_{\mathrm{mn}}=$ interactions of effects; and $\mathrm{E}_{\mathrm{ijklmn}}=$ random error.

Linear contrasts were used to evaluate differences between subclasses of location, sire-fertility group, TAI, parity, and season of AI. Results are presented as least squares means as well as odds ratios for location, sirefertility group, timing of AI, parity, and season of AI (Table 2). First-service PR (simple averages) of individual sires within farm and overall are shown in Table 3 , and individual sires within time of $\mathrm{AI}$ are in Table 4 , although sire is a random effect. Individual sire averages were unadjusted for model effects, and tested by $\chi^{2}$.

\section{RESULTS}

Timing of AI did not influence first AI PR. Pregnancy rates for $\mathrm{AI}$ at 0 and $24 \mathrm{~h}$ after $\mathrm{GnRH}$ were $26.7 \pm$ 2.1 and $25.7 \pm 2.3 \%$, respectively (Table 2 ). Parity and season of AI were found to affect $(P \leq 0.05)$ first AI PR (Table 2). First AI PR for average and high sire-fertility groups were $23.2 \pm 2.2$ and $29.4 \pm 2.5 \%$, respectively 
Table 3. First-service pregnancy rates (PR, simple average) by sire and farm using a Presynch + Ovsynch synchronization program

\begin{tabular}{llll}
\hline & & & $\begin{array}{l}\text { Overall } \\
\text { pregnancy } \\
\text { rate }\end{array}$ \\
\hline & Farm 1 & Farm 2 & \\
\cline { 2 - 4 } A & $22.8(92)$ & $18.7^{\mathrm{a}}(107)$ & $20.6^{\mathrm{a}}(199)$ \\
$\mathrm{B}$ & $28.4(88)$ & $27.7^{\mathrm{ab}}(101)$ & $28.0^{\mathrm{ab}}(189)$ \\
$\mathrm{C}$ & $32.9(85)$ & $25.7^{\mathrm{ab}}(101)$ & $29.0^{\mathrm{ab}}(186)$ \\
$\mathrm{D}$ & $32.2(87)$ & $33.3^{\mathrm{b}}(100)$ & $32.6^{\mathrm{b}}(187)$ \\
$\mathrm{E}$ & $35.4(82)$ & $26.0^{\mathrm{ab}}(104)$ & $30.1^{\mathrm{b}}(186)$ \\
F & $31.0(87)$ & $27.6^{\mathrm{ab}}(98)$ & $29.2^{\mathrm{b}}(185)$ \\
\hline
\end{tabular}

${ }^{\mathrm{a}, \mathrm{b}}$ Mean percentages within column bearing different superscript letters differ $(P \leq 0.05)$.

${ }^{1}$ No. of inseminations.

$(P=0.12 ;$ Table 2$)$. No interaction was detected between sire-fertility group and TAI $(P=0.95)$. Pregnancy rates for cows bred to high-fertility sires at 0 or $24 \mathrm{~h}$ after GnRH were $26.7 \pm 2.1$ and $25.7 \pm 2.3 \%$, respectively.

Lactation number was found to influence first AI PR. Pregnancy rates for first-lactation cows differed $(P \leq$ 0.05 ) from that of cows in their second or third and greater lactation $(31.8 \pm 2.5,24.0 \pm 2.7$, and $23.4 \pm$ $2.6 \%$, respectively, Table 2 ). No difference was detected among cows in later lactations. Odds ratios indicated that cows in first lactation were 53\% more $(P \leq 0.05)$ likely to achieve pregnancy at first AI than cows in third and greater lactation and were $49 \%$ more $(P \leq$ 0.05 ) likely to achieve pregnancy at first AI than cows in their second lactation (Table 2).

Cows receiving AI during April through June were $66 \%$ less $(P \leq 0.05)$ likely to become pregnant than cows bred from October through January (Table 2). No differences were detected between cows receiving $\mathrm{AI}$ in adjacent seasons. No effects of farm or interactions with farm were detected. Therefore, interaction effects were eliminated from the model. No other interaction effects in the model were significant.

Table 4. First-service pregnancy rates (PR, simple average) by sire and timing of $\mathrm{AI}$ (either at 0 or $24 \mathrm{~h}$ after $\mathrm{GnRH}$ administration) in a Presynch + Ovsynch synchronization program

\begin{tabular}{lll}
\hline & \multicolumn{2}{c}{ Time of AI after GnRH, h } \\
\cline { 2 - 3 } Sire & 0 & 24 \\
\cline { 2 - 3 } & $25.2(103)$ & \\
A & $30.1(93)$ & $15.6^{\mathrm{a}}(96)$ \\
B & $27.3(110)$ & $26.0^{\mathrm{ab}}(96)$ \\
C & $32.7(101)$ & $31.6^{\mathrm{b}}(76)$ \\
D & $28.9(114)$ & $32.6^{\mathrm{b}}(86)$ \\
E & $33.3(99)$ & $31.9^{\mathrm{b}}(72)$ \\
F & & $24.4^{\mathrm{ab}}(86)$ \\
\hline
\end{tabular}

${ }^{\mathrm{a}, \mathrm{b}}$ Mean percentages within column bearing different superscript letters differ $(P \leq 0.05)$.

${ }^{1}$ No. of inseminations.

\section{DISCUSSION}

A reason cited by Portaluppi and Stevenson (2005) for improved PR following GnRH and AI $72 \mathrm{~h}$ after $\mathrm{PGF}_{2 \alpha}$ compared with GnRH $48 \mathrm{~h}$ and AI $72 \mathrm{~h}$ after $\mathrm{PGF}_{2 \alpha}$ was a greater time allowance for development of a mature ovulatory follicle, possibly allowing for improved subsequent luteal function. Walker et al. (1996) used the Heatwatch system to determine the onset of estrus, defined as the first standing mount with a minimum of 3 standing mounts in $4 \mathrm{~h}$, after administration of $\mathrm{PGF}_{2 \alpha}$ to be $73.1 \pm 2.8 \mathrm{~h}$. Using these data from spontaneously occurring estrus and ovulation or from $\mathrm{PGF}_{2 \alpha}$-induced estrus, one may extrapolate that more than $48 \mathrm{~h}$ may be needed for the interval between $\mathrm{PGF}_{2 \alpha}$ and GnRH injections in an Ovsynch protocol for development of a mature follicle.

Sire-fertility groups did not differ for first AI PR. Sires were selected on ERCR values (average $=-1$ vs. high $=\geq+3$ ) to estimate a possible interaction of sirefertility groups with timing of AI in a TAI protocol. The values of ERCR are expressed as a deviation from the average of zero of a particular breed (Pecsok et al., 1994). The 3 average sires were selected to be at least 4 ERCR points below the 3 high-fertility sires. Least squares means for PR in this study for average and high sire-fertility groups were 23.2 and $29.4 \%$, respectively, a slightly greater difference than expected. When fertility advantages are needed, selection of groups of sires with above-average ERCR values is a practical recommendation. Semen from high-fertility sires has economic value beyond genetic potential. Pecsok et al. (1994) found that on average a 1-ERCR point increase is worth $\$ 2$ per unit of semen to the producer.

From the start of the study in November 2003 to May 2004,5 of 6 sires utilized in the study deviated at least 1-ERCR point from their original ERCR value. Sire F was selected with a +4 ERCR and a repeatability of $70 \%$ and was +1 with a repeatability of $89 \%$ in May 2004. The ERCR value reported in November 2004 for sire $\mathrm{F}$ was +2 with repeatability of $94 \%$. Thus, in retrospect, sire F may not be a high-fertility sire based on the selection criterion of this study. Sire A, with a repeatability of $99 \%$, was the only sire that did not deviate in ERCR value from November to May. On farm 1, no differences in PR by sire were detected (Table 3). On farm 2 , sire $\mathrm{D}$ resulted in greater $(P<0.05) \mathrm{PR}$ than sire A (33.3 vs. $18.7 \%)$, whereas sire A had a lesser ( $P$ $<0.05$ ) overall PR when compared with the other 5 sires. Sire A may be an outlier, because no difference in the overall PR of sires B, C, D, E, and F was detected. In contrast, the May 2004 ERCR value for sire A was the smallest of the 6 sires (Table 1). 
Timing of AI at 0 or $24 \mathrm{~h}$ following final GnRH injection produced similar PR of 26.7 and $25.7 \%$, respectively. The objective of this study was to determine if sire fertility differed by timing of AI. In fact, the respective sire-fertility groups performed similarly at each time of AI. No differences between AI times within sires or across the 6 sires within the $0 \mathrm{~h}$ AI time were found (Table 4). At the 24-h AI time, sire A had a lesser $(P<$ 0.01) PR compared with sires C, D, and E. These results were unexpected because Macmillan and Watson (1975) reported that sires of different fertility perform differently depending on the time of AI relative to estrus. Macmillan and Watson (1975) selected groups of sires of different fertility to use to AI cows at different stages of estrus. Although sire-fertility groups differed, stage of estrus at AI affected fertility more. In their study, CR was not comprised for high fertility sires at any stage of estrus, although sires of below average and average fertility produced reduced $\mathrm{CR}$ when $\mathrm{AI}$ occurred during early estrus.

An interaction between sire-fertility groups and time of AI may have been masked by the relatively narrow interval of ovulation time in the TAI protocol. Pursley et al. (1995) reported that ovulation occurred in 18 cows 26 to $32 \mathrm{~h}$ after $\mathrm{GnRH}$ administration with the greatest number of cows ovulating at $28 \mathrm{~h}$ after $\mathrm{GnRH}$ administration. In contrast, Macmillan and Watson (1975) compared CR obtained by AI technicians in a once-daily AI protocol. Each morning the AI technicians inseminated cows detected in estrus during the previous $24 \mathrm{~h}$. Time of initial estrus detection during the 24-h period was used to categorize the stage of estrus at AI. Estrus detection was the responsibility of 63 herd owners and the consistency in detection of the onset of estrus was unknown. Average time of ovulation from the onset of estrus activity was reported to be $27.6 \pm 5.4 \mathrm{~h}$ (Walker et al., 1996). Variation among cows allowed to experience spontaneous ovulation was greater than among those having synchronized ovulation (Pursley et al., 1995), possibly contradicting the interpretation of results obtained by Macmillan and Watson (1975).

Pursley et al. (1998) reported no difference in CR when $\mathrm{AI}$ occurred at the same time or $24 \mathrm{~h}$ after $\mathrm{GnRH}$ administration. Studies have shown increased CR when AI occurred approximately $12 \mathrm{~h}$ before ovulation in synchronized ovulation protocols and natural ovulation. Pursley et al. (1998) reported a quadratic effect for cows receiving $\mathrm{AI}$ at $0,8,16,24$, or $32 \mathrm{~h}$ after $\mathrm{GnRH}$. The highest CR, $45 \%$, occurred when AI was performed $16 \mathrm{~h}$ after the final GnRH administration. Dalton et al. (2001) contended that AI at $12 \mathrm{~h}$ after the onset of estrus provided a compromise between potentially lower fertilization rates for AI occurring at the onset of estrus and reduced embryo quality due to increased degenerate embryos when AI occurred $24 \mathrm{~h}$ after the onset of estrus. In a large field study (Dransfield et al., 1998), we used a radiotelemetric estrus-detection system and reported that the highest CR occurred when cows were inseminated 4 to $12 \mathrm{~h}$ after the onset of estrus, defined by the first standing event. These studies support the basis of the a.m.-p.m. guideline established by Trimberger (1948) in which AI should occur approximately $12 \mathrm{~h}$ after detected estrus, when frequency of detected estrus was at least twice daily. Our study indicated that timing of AI concurrent with administration of GnRH $54 \mathrm{~h}$ after $\mathrm{PGF}_{2 \alpha}$ or $\mathrm{AI}$ at $24 \mathrm{~h}$ after $\mathrm{GnRH}$ is unrelated to $\mathrm{PR}$ and no interaction existed between timing of AI and PR of sire-fertility group.

Parity differences also were revealed in our study. Our results conflict with the review by Lucy (2001) in which first-lactation cows were stated to have poorer fertility at first AI. Furthermore, Navanukraw et al. (2004) reported no difference among parities for cows treated with an Ovsynch or Presynch + Ovsynch protocol. Other studies (Cartmill et al., 2001; Portaluppi and Stevenson, 2005) reported that CR was greater in firstthan in multiple-lactation cows.

Seasonal differences in our study may not be explained by environmental factors, but by compliance to the hormone administration sequence in the Presynch + Ovsynch protocol and AI at the prescribed time in the protocol. Of the 219 cows not bred according to the first AI protocol, 93 were removed during April to June compared with 51 during October to January. Greatest percentage of cows bred off-protocol occurred in April to June (23\%) when PR was less than October to January when fewer cows (9\%) were bred off-protocol. Only seasons 1 and 3 differed in PR. Removing cows from the study was the responsibility of the farm employees. Insemination of cows detected in estrus after one of the initial $\mathrm{PGF}_{2 \alpha}$ administrations was the major error in compliance.

\section{CONCLUSIONS}

Results of this study indicated that use of high-fertility sires resulted in $6 \%$ greater PR, greater than the target of $4 \%$, but not different because of variability among sires in fertility groups used in the study. More importantly, no PR difference was detected in the timing of AI for either sire-fertility group for TAI cows inseminated at first service. Previous studies indicated that $\mathrm{AI}$ at 12 to $16 \mathrm{~h}$ before ovulation resulted in a compromise between functional sperm loss and an aging ovum, probably resulting in less selection of competent sperm. Extreme AI times were evaluated during this study, thus it would be assumed that average- and high-fertility sires would probably achieve better PR 
when $\mathrm{AI}$ occurred at 8 to $16 \mathrm{~h}$ after $\mathrm{GnRH}$ administration. When applying TAI in conjunction with very precise control of follicular development and ovulation using a protocol such as Presynch + Ovsynch, effects of sperm longevity may tend to be minimized because even bulls with a short duration of sperm longevity might adequately cover the fertile ovulation window to achieve acceptable CR.

\section{ACKNOWLEDGMENTS}

This research was made possible by cooperation and assistance of individuals at Myers Dairy, Inc. (Union Grove, NC) and Rocky Creek Dairy, Inc. (Olin, NC). Appreciation also is expressed to Genex Cooperative, Inc. (Shawano, WI) for financial assistance and donation of semen, and to Pfizer Animal Health (New York, $\mathrm{NY}$ ) for donation of Lutalyse.

\section{REFERENCES}

Britt, J. H., R. G. Scott, J. D. Armstrong, and M. D. Whitacre. 1986. Determinants of estrous behavior in lactating Holstein cows. J. Dairy Sci. 69:2195-2202.

Butler, W. R. 2000. Nutritional interactions with reproductive performance in dairy cattle. Anim. Reprod. Sci. 60-61:449-457.

Cartmill, J. A., S. Z. El-Zarkouny, B. A. Hensley, G. C. Lamb, and J. S. Stevenson. 2001. Stage of cycle, incidence, and timing of ovulation, and pregnancy rates in dairy cattle after three timed breeding protocols. J. Dairy Sci. 84:1051-1059.

Clay, J. S., and B. T. McDaniel. 2001. Computing mating bull fertility from DHI nonreturn data. J. Dairy Sci. 84:1238-1245.

Dalton, J. C., S. Nadir, J. H. Bame, M. Noftsinger, R. L. Nebel, and R. G. Saacke. 2001. Effect of time of insemination on number of accessory sperm, fertilization rate, and embryo quality in nonlactating dairy cattle. J. Dairy Sci. 84:2413-2418.

Dransfield, M. B. G., R. L. Nebel, R. E. Pearson, and L. D. Warnick. 1998. Timing of insemination for dairy cows identified in estrus by a radiotelemetric estrus detection system. J. Dairy Sci. 81:1874-1882.

Lopez, H., L. D. Satter, and M. C. Wiltbank. 2004. Relationship between level of milk production and estrous behavior of lactating dairy cattle. Anim. Reprod. Sci. 81:209-223.
Lucy, M. C. 2001. Reproductive loss in high-producing dairy cattle: Where will it end? J. Dairy Sci. 84:1277-1293.

Macmillan, K. L., and J. D. Watson. 1975. Fertility differences between groups of sires relative to the stage of oestrus at the time of insemination. Anim. Prod. 21:243-249.

Navanukraw, C., D. A. Redmer, L. P. Reynolds, J. D. Kirsch, A. T. Grazul-Bilska, and P. M. Fricke. 2004. A modified presynchronization protocol improves fertility to timed artificial insemination in lactating dairy cows. J. Dairy Sci. 87:1551-1557.

Nebel, R. L., and M. L. McGilliard. 1993. Interactions of high milk yield and reproductive performance in dairy cows. J. Dairy Sci. 76:3257-3268.

Pecsok, S. R., M. L. McGilliard, and R. L. Nebel. 1994. Conception rates. 2. Economic value of unit differences in percentage of sire conception rates. J. Dairy Sci. 77:3016-3021.

Portaluppi, M. A., and J. S. Stevenson. 2005. Pregnancy rates in lactating dairy cows after presynchronization of estrus cycles and variations of the Ovsynch protocol. J. Dairy Sci. 88:914-921.

Pursley, J. R., M. O. Mee, and M. C. Wiltbank. 1995. Synchronization of ovulation in dairy cows using $\mathrm{PGF}_{2 \alpha}$ and $\mathrm{GnRH}$. Theriogenology 44:915-923.

Pursley, J. R., R. W. Silcox, and M. C. Wiltbank. 1998. Effect of time of artificial insemination on pregnancy rates, calving rates, pregnancy loss, and gender ratio after synchronization of ovulation in lactating dairy cows. J. Dairy Sci. 81:2139-2144.

Saacke, R. G., S. Nadir, J. Dalton, J. Bame, J. M. DeJarnette, S. Degelos, and R. L. Nebel. 1994. Accessory sperm evaluation and bull fertility - an update. Pages 57-67 in Proc. Natl. Assoc. of Anim. Breeders 15th Tech. Conf. on AI and Reprod., Columbia, MO.

SAS Institute. 2002-2003. SAS User's Guide: Statistics. Version 9.1 for Windows. SAS Inst., Inc., Cary, NC.

Trimberger, G. W. 1948. Breeding efficiency in dairy cattle from artificial insemination at various intervals before and after ovulation. Nebraska Agric. Exp. Stn. Res. Bull. 153:1.

Vasconcelos, J. L. M., R. W. Silcox, G. J. M. Rosa, J. R. Pursley, and M. C. Wiltbank. 1999. Synchronization rate, size of the ovulatory follicle, and pregnancy rate after synchronization of ovulation beginning on different days of the estrous cycle in lactating dairy cows. Theriogenology 52:1067-1078.

Walker, W. L., R. L. Nebel, and M. L. McGilliard. 1996. Time of ovulation relative to mounting activity in dairy cattle. J. Dairy Sci. 79:1555-1561.

Washburn, S. P., W. J. Silvia, C. H. Brown, B. T. McDaniel, and A. J. McAllister. 2002. Trends in reproductive performance in southeastern Holstein and Jersey DHI herds. J. Dairy Sci. 85:244-251. 